\title{
Approach for Quantifying Rare Earth Elements at Low keV
}

\author{
Heather Lowers
}

\section{USGS, United States}

The challenges of analyzing bastnaesite $\left(\mathrm{REECO}_{3} \mathrm{~F}\right)$ and hydroxylbastnaesite $(\mathrm{REECO} 3 \mathrm{OH})$ include beam sensitivity, quantification of light elements in a heavy element matrix, the presence of elements that cannot be analyzed by electron probe microanalysis $(\mathrm{H})$, and the use of $\mathrm{x}$-ray lines whose physical constants are not well known. To overcome some of these challenges, $\mathrm{Ca}, \mathrm{La}, \mathrm{Ce}, \mathrm{Pr}, \mathrm{Nd}$, and $\mathrm{Sm}$ were analyzed at 15 $\mathrm{keV}$ accelerating voltage and the light elements $(\mathrm{C}, \mathrm{O}, \mathrm{F})$ were analyzed at $7 \mathrm{keV}$ accelerating voltage [1]. This approach is ideal for samples that are homogeneous within the volume analyzed. However, for the bastnaesite of interest, this solution is unsatisfactory because backscattered electron imaging reveals chemical variations at scales of less than $1 \mu \mathrm{m}$ (fig. 1). Monte Carlo simulations and wavescans of the rare earth element (REE) M family of x-rays were evaluated to determine the best analytical approach.

Monte Carlo simulations using Casino v2.42 [2] were run on a substrate of $\mathrm{CeCO}_{3} \mathrm{~F}$ with a density of 5.00 $\mathrm{g} / \mathrm{cm} 3$ at $15 \mathrm{keV}$ and $7 \mathrm{keV}$ accelerating voltage. Depth distribution curves, $\varphi(\rho z)$, reveal x-ray generation at $15 \mathrm{keV}$ for the Ce L shell x-rays approaches $1.0 \mu \mathrm{m}$ whereas the depth of Ce $\mathrm{M}$ shell $\mathrm{x}$-ray generation at $7 \mathrm{keV}$ is less than $0.4 \mu \mathrm{m}$ (fig. 1). Similarly, the $\mathrm{K}$ shell $\mathrm{x}$-ray generation depth for $\mathrm{C}$, O, and $\mathrm{F}$ at $7 \mathrm{keV}$ is also less than $0.4 \mu \mathrm{m}$ (fig. 1). These simulations demonstrate an accelerating voltage of $7 \mathrm{keV}$ or less and use of the REE M x-rays is necessary to acquire chemical information from the same volume of material for the light and heavy elements. Bastnaesite contains all REEs and therefore one must consider the energy of the highest X-ray line of interest, namely the Lu M $\gamma$ at $1.83 \mathrm{keV}$, to achieve an overvoltage $(\mathrm{Eo} / \mathrm{Ec})$ greater than 2. Bastnaesite is also an insulator and requires a conductive coating, therefore $7 \mathrm{keV}$ was used to avoid contributions of the coating material to the analysis given the above constraints.

The USNM REE phosphate standards, Edinburgh REE glasses, $\mathrm{CeO}_{2}, \mathrm{LaB}_{6}$, and the metals of Sm, Dy, $\mathrm{Gd}$, Er, and $\mathrm{Yb}$ were selected to evaluate the peak overlaps of the $\mathrm{M}$ family $\mathrm{x}$-ray lines. The materials were coated with $\sim 5 \mathrm{~nm}$ iridium with a Leica ACE600 prior to analysis. Full spectrometer wavescans were collected at $7 \mathrm{keV}$ accelerating voltage, $50 \mathrm{nA}$ beam current, and $20 \mu \mathrm{m}$ beam diameter on a JEOL $8530 \mathrm{~F}$ Plus using TAP and TAPL crystals. The step size was $0.109 \mathrm{~mm}$ along the length of the spectrometer with a dwell of 3 seconds at each step. M $\alpha$ and $\mathrm{M} \beta$ lines are broad and not individually resolved for the light REE but become more separated and sharper with increasing atomic number (fig. 2A). M $\gamma$ and $\mathrm{M} \zeta$ lines for each REE are also present across the spectrometer range further complicating peak interference corrections (fig. 2A). The peak positions and overall shape for the $\mathrm{Ce} \mathrm{M} \alpha$ and $\mathrm{M} \beta$ lines vary with the coordination of the element (fig. 2B). Significant shifts in position and shape were not observed when comparing the $\mathrm{Ce} \mathrm{M} \gamma$ peaks of $\mathrm{CeO}_{2}$ and $\mathrm{CePO}_{4}$ (fig. 2B). Similar results were seen when comparing the available REE metal to the phosphate (Sm, Dy, Gd, Er, Yb). These wavescans indicate the use of the $\mathrm{M} \zeta$ or $\mathrm{M} \gamma$ lines if matrix matched standards are not available.

Any use of trade, firm, or product names is for descriptive purposes only and does not imply endorsement by the U.S. Government. 


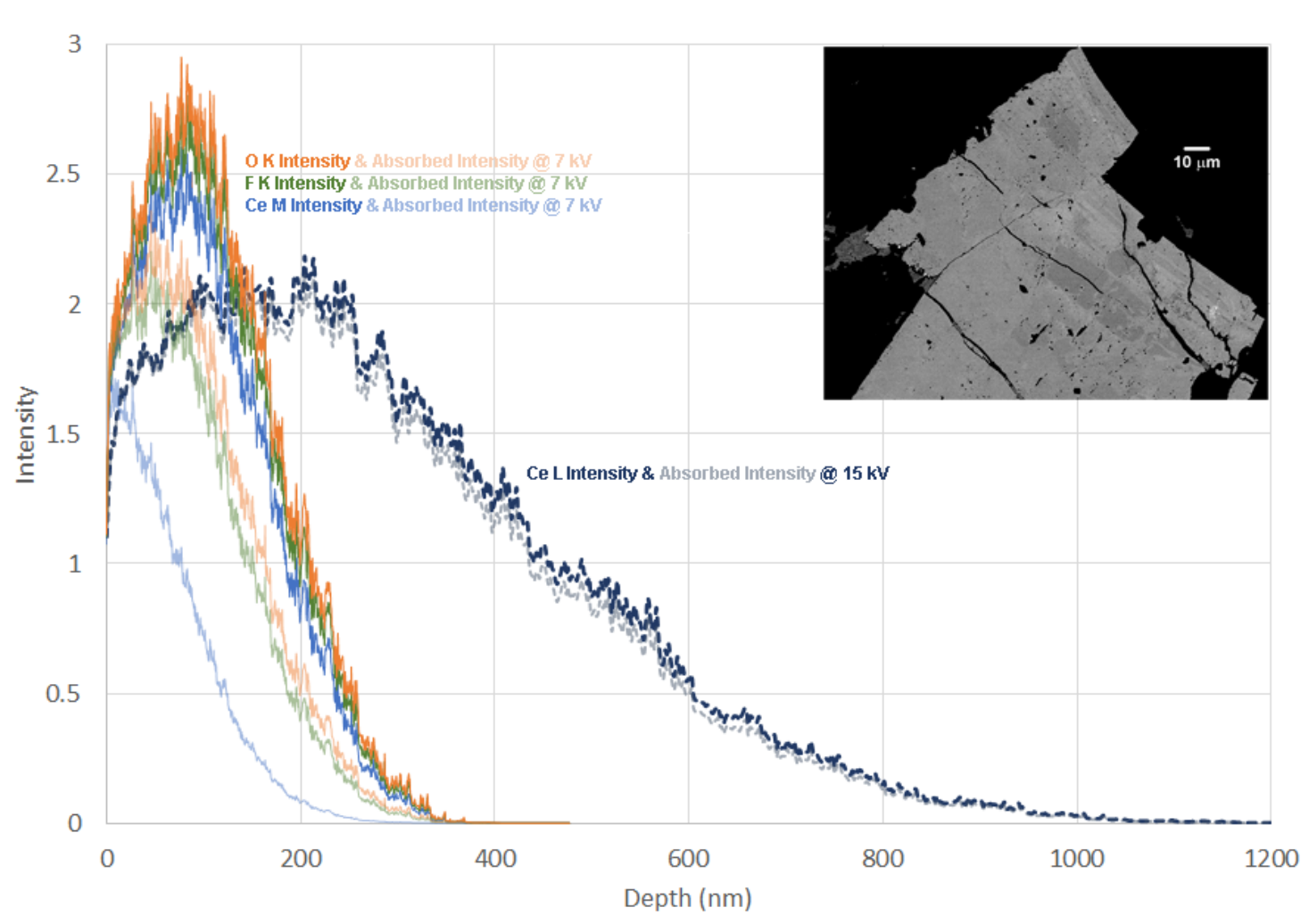

Figure 1. Depth distribution curves, $\varphi(\rho z)$, for $\mathrm{Ce}, \mathrm{F}$, and $\mathrm{O}$ at $7 \mathrm{keV}$ and $\mathrm{Ce}$ at $15 \mathrm{keV}$. A backscattered electron image of bastnaesite shows the fine spatial variation of the composition. 


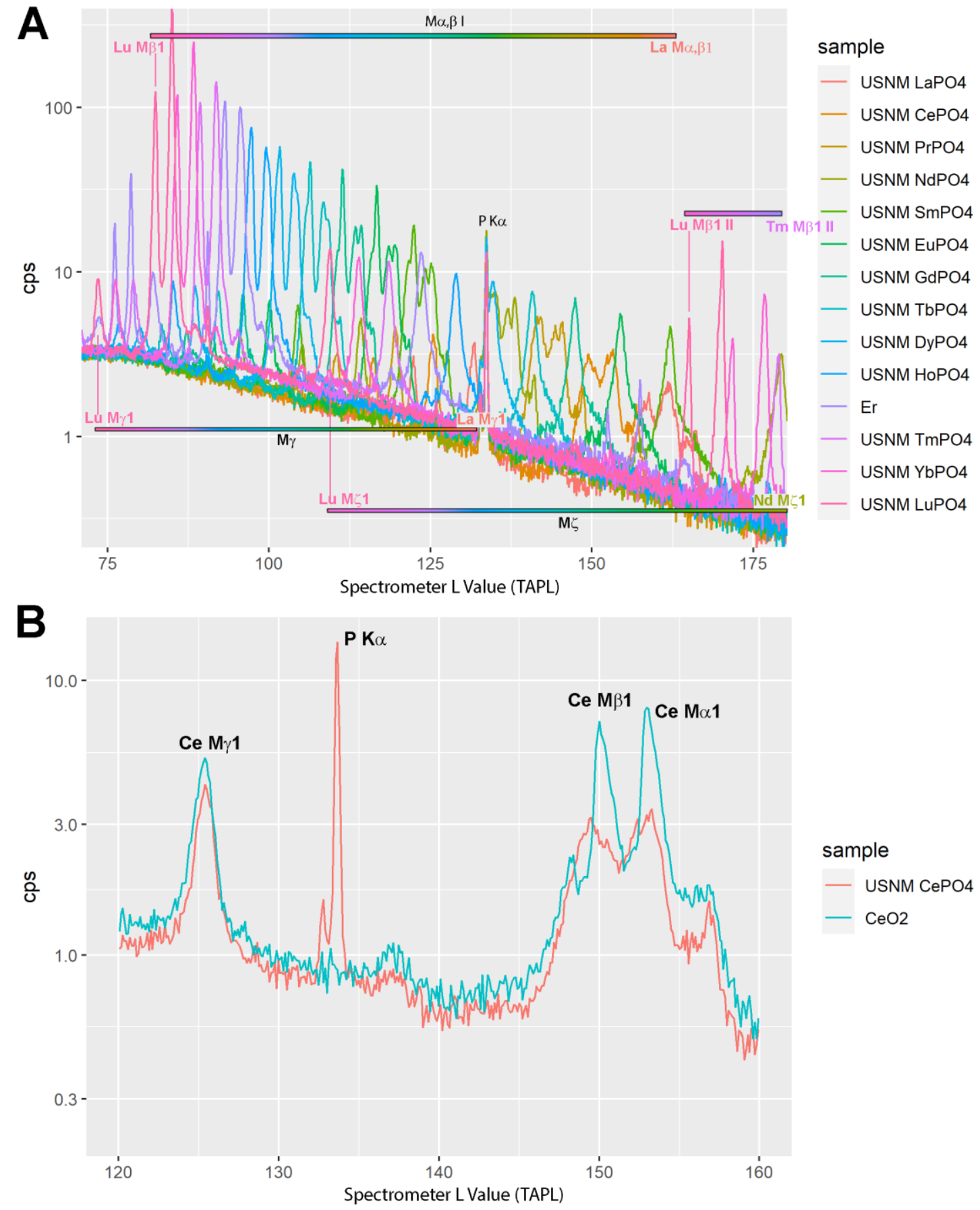

Figure 2. A. Wavescans on the USNM REE phosphates demonstrate multiple peak overlaps due to M $\alpha$, $\mathrm{M} \beta, \mathrm{M} \gamma$, and $\mathrm{M} \zeta$ x-ray lines. B. Spectrometer scans across the $\mathrm{M} \alpha, \mathrm{M} \beta$, and $\mathrm{M} \gamma$ peaks in CePO 4 and $\mathrm{CeO} 2$ demonstrate clear changes in peak position and shape for the $\mathrm{M} \alpha$ and $\mathrm{M} \beta \mathrm{x}$-ray lines but no resolvable change in the $\mathrm{M} \gamma \mathrm{x}$-ray line.

\section{References}

[1] H. Lowers and G. Swayze, Microscopy and Microanalysis 26 (S2) (2020), p. 1884. doi: $10.1017 /$ S1431927620019704

[2] Drouin. D. et al., Scanning, 29 (2007), p. 92. doi:10.1002/sca.20000 